\title{
Social Connections in the Inner City: Examination across the Life Course
}

\author{
Margaret E. Ensminger* \\ Bloomberg School of Public Health, USA \\ Hee-Soon Juon \\ Bloomberg School of Public Health, USA \\ Rosalyn Lee \\ previously with NORC at the Dept. of Substance Abuse, Mental Health and Criminal \\ Justice Studies, University of Chicago, USA \\ Sophia Y. Lo \\ Bloomberg School of Public Health, USA
}

${ }^{*}$ Corresponding author. Email: mensming@jhsph.edu

\begin{abstract}
Social connectedness has been shown to be related to health and well-being, yet there is little knowledge about its developmental and intergenerational origins. We examine the childhood, family, and neighbourhood origins of social connectedness in young adulthood in a cohort of African American children ( $N=1242)$ from Chicago followed since 1966. The five measures of social connections are: political involvement, organizational membership, church involvement, family ties, and friend ties. In multivariate analyses, predictors of social connectedness were found across the life course: first grade social adaptation to school, childhood family resources, family social participation, adult neighbourhood characteristics, social class, and marital status. We conclude that adult social connections have roots in childhood behaviour and social involvement, family resources and family social connections as well as one's own resources and the neighbourhood where one lives.
\end{abstract}

\section{Keywords}

Life Course Study; Longitudinal Research; Social Connections; Social Capital; African American; Intergenerational; Multi-Level; Neighbourhood; Social Class; Family; Social Adaptation

\section{Supporting Agencies}

National Institutes of Health, National Institute of Drug Abuse, National Institute of Aging

\section{Introduction}

Although social connectedness has been shown to have beneficial effects on physical and psychological well being, employment, children's development, and the absence of crime (Berkman et al, 2000; House, Landis, \& Umberson, 1988; Sampson \& Laub, 1993; Runyan et al, 1998; Furstenberg \& Hughes, 1995), there has been limited study of those conditions that lead to social connections. We examine childhood, family, and neighbourhood characteristics that influence social connections in a community cohort of African Americans followed from ages 6 to 32 . 
Concepts of social connectedness relate to social integration at the broadest level, and to social capital, social networks, social support, and social isolation (Berkman et al, 2000). Social ties to others start at the moment of birth and continue to be important for well-being throughout the life course. According to an Institute of Medicine report (2003, p. 64), 13 prospective studies have documented that people who are isolated or disconnected from others are at increased risk of dying prematurely. Social connectedness has also been related to better health behaviours (Umberson, 1987; Berkman et al, 2000; Lindstrom et al, 2003), less delinquency and criminal behaviour (Hirschi, 1969; Sampson \& Laub, 1993), as well as lower unemployment (Kasinitz \& Rosenberg, 1996). Several cross-sectional studies, however, have not found relationships between social participation and various measures of health (Ellaway \& Macintyre, 2007).

\section{How social connections are protective}

Several mechanisms may explain the protectiveness of social connectedness. Social ties help encourage compliance with social norms so that those with many social connections are less likely to engage in behaviours that may be injurious to themselves or others (assuming that the norms favour protective behaviours). This is a major premise in social control theory (Hirschi, 1969). The existence of social ties increases the likelihood that others are able to observe and thus exert pressure. Also, the presence of important social ties helps motivate individuals to regulate themselves (Umberson, 1987). From this perspective, social relationships give meaning and purpose to one's life through the establishment and maintenance of social ties, institutional relationships, and community involvement (Burton, 1998; Seeman, 1996). According to a social capital perspective, social connections provide resources to individuals that can be used to achieve their interests (Coleman, 1988; Portes, 1998). Coleman, an originator of the term social capital, saw youth development as influenced both by the social capital within the family (i.e. the time and investment made in children) and the social capital outside the family (i.e. the family social relationships with other families and community institutions). In addition, the importance of "weak ties" has also been recognized (Granovetter, 1973). Much of the literature on social relationships has focused on close ties that individuals have with family and friends. However, the advantage of ties with those who are outside one's own immediate circle, "weak ties", allow an individual to reach beyond immediate family and close friends to those outside one's own social circle. Such contacts play an important role in the diffusion of information and resources across society, including links to education and employment. Since "weak ties" are more likely to convey dissonant or new information than are stronger ties with family or friends, they may be particularly important in bringing about individual changes in ideas and behaviours (Granovetter, 1973).

According to Wilson's analysis of inner city areas in the U.S., weak ties may be especially important for those who live in neighbourhoods that are isolated from the mainstream. Wilson (1987) argues that weak ties have diminished over time in inner city areas resulting in disadvantage and social isolation, defined as the absence of social connections. The absence of connections, referred to by Wilson, is not those to family or friends, but to "the lack of contact or of sustained interaction with individuals and institutions that represent mainstream society" (p. 60). Isolation, he argues, increased following changes to policies and laws aimed at dismantling residential segregation. Prior to these changes, African American communities were largely characterized by class heterogeneity such that middle-class professional, working-class, and lower-class families co-mingled within neighbourhoods. Though these neighbourhoods had high rates of poverty and unemployment, those residents who were poor and unemployed still had contact with neighbours who were employed and who interacted with the broader society through their employment or participation in community institutions. The middle class presence in poor African American neighbourhoods, according to Wilson, helped regulate norms, values and sanctions while serving as a link to outside information and resources. With the leaving of middle-class families from the inner city, those who were left behind had fewer connections to the broader society. His argument does not diminish the importance of ties to family and close friends, but rather emphasizes the importance of ties to those outside the immediate social circle, especially for those whose primary social relationships lacked ties to the broader societal institutions.

\section{Predictors of social connections}

Few studies have examined the influences on social connections over the life course, whether these connections are to family and friends or to civic activities and organizations. In a longitudinal study, 
Myers (1999) found that young adults who had moved less frequently as children, had parents who were involved in church as they were growing up, and had not changed communities for five years had higher feelings of community attachment than others. Graves and colleagues (1998) in a longitudinal study of medical students found that those who had been raised in a family involved in church, had more educated fathers, and did not lose a parent to death or divorce were more likely to have a higher number of group memberships 22 years after medical school. Closeness to parents as measured during medical school was related to later social closeness (indicated by the number of family members and friends that respondents felt they could feel at ease with and talk with). These few studies do suggest that one's social connections are related to the social connections of parents and family members; however, there is no body of literature that demonstrates this.

There has been substantial evidence of generational continuity in education and occupation, (e.g. Blau \& Duncan, 1967; Harding et al, 2005) yet there has been little study of continuity in social connections across generations. We might expect that those whose parents have been involved in community and civic activities would be more likely to be similarly involved than those whose families have not been involved. Yet, there is relatively little evidence of this intergenerational continuity or little evidence of the continuity in social connections across the life course. Again, we would expect that those individuals who were connected to family and friends and were involved in social organizations at one stage of life would be more likely to be involved at later stages. Despite the important advantages that social connections seem to confer, there has been little study of their continuity across the life course or across generations.

\section{Conceptual framework}

Our goal in the present study was to estimate the long-term and developmental influences on young adults' social connections to family, friends, church, organizational ties, and political ties. These connections represent the breadth of ties from close family and friends to the broader societal, civic, and organizational connections. We have hypothesized several pathways to social connections over the life course. One pathway focuses on family social and economic resources. A second pathway centres on the family's own social connections over the life course. A third pathway focuses on the individual's past social connections in earlier stages of the life course (i.e. childhood and adolescence). Finally, the model acknowledges the potential importance of neighbourhood context on social connections. Our conceptual model is one of the first to focus on the causal processes linking family social resources, childhood social connections, and neighbourhood context to social connections in the adult years.

Our study draws on several perspectives: a social field perspective that emphasizes the developmental importance of the relationships that individuals have within important social contexts across the life course (Kellam et al, 1975); a life course perspective that focuses on the linked lives of family members noting that lives are lived interdependently (Elder, 1998); and a neighbourhood ecology model that recognizes the importance of one's residential context in influencing opportunities for social connections (Fernandez \& Harris, 1992; Oliver, 1988; Rankin \& Quane, 2000).

The social field perspective emphasizes the importance of key social fields in individuals' lives. For example, the family and school contexts are key for children; as they mature, peers and intimate partners become important social contexts. Employment, one's own family of procreation, and eventually one's children's families are potentially important social fields. The perspective argues within each of these social fields there are important raters who evaluate one's performance (e.g. the parents in the family, the teacher in the classroom, the supervisor at work), and that these ratings have importance to the individual's adaptation to the current social fields as well as implications for future adaptation in key social fields. It is not that the raters are accurate in some objective sense, but that their judgments have repercussions for the individual. There is some continuity in an individual's adaptation, both across social fields and across time (Kellam et al, 1975; Kellam \& Rebok, 1992). Thus, we would hypothesize that those who were rated as doing well in social relationships early in the life course would have more social connections as adults.

The concept of linked lives is paramount in the life course perspective as articulated by Elder (1998). Historical events and individual experiences are connected through the family and the experiences of one's family members are shared with others through their relationships. Kinder (2006) argues that political participation starts in the family with parents setting the stage for political discussion. Children acquire (or not) a set of political predispositions and skills that influence their participation later. The most robust finding with regard to family influences on social connections is that children from homes 
with more income, more skills, and more education are more likely to take part in all forms of participation (Kinder, 2006; Rosenstone \& Hansen, 1993). Here, we would hypothesize that children of parents who are active in community, civic, and religious organizations would be socialized to be active members of these groups. Modelling of parents' behaviours, recruitment by parents, or social training might all be responsible for this hypothesized continuity.

A third influence on social connectedness may be the context where one lives. The opportunities for social connectedness in terms of the availability of churches, and community and political organizations are likely to vary by neighbourhood. In addition, the norms of social connections may vary by neighbourhood. Several studies have documented that neighbourhood characteristics are associated with residents' social connectedness as measured in various ways (Fernandez \& Harris, 1992). In a study of inner city Chicago African American families, Rankin and Quane (2000) found modest neighbourhood effects on social isolation, measured by individual and family participation in community organizations and by the composition of the individual's network. Individual-level characteristics, such as socioeconomic status, were the strongest predictors of social network composition and individual and family participation in community organizations. In a study of social networks of African Americans in Los Angeles, Oliver (1988) found those living in the most economically depressed neighbourhoods were more likely to have local ties with neighbours and family members and less likely to have organizational ties. Similar to the "weak ties" concept, Oliver suggests the strength of these local ties may inhibit the building of links to formal groups and those outside their immediate neighbourhood. Most of these studies have been cross-sectional and have not integrated the neighbourhood context with longitudinal information on the family or the prior social involvements of the study participants.

We hypothesize that social connectedness will vary by neighbourhood characteristics. Specifically, we will examine the percent poor in the neighbourhood, the percent black in the neighbourhood and the percent white collar workers who live in the neighbourhood. Neighbourhoods that are poor are less likely to have the resources to support organizations that residents may be involved with. A higher percent of white collar workers in a neighbourhood is intended to be an indicator of a middle class presence, and is hypothesized to be related to higher rates of participation. For African Americans, living in a neighbourhood that has a higher percentage of blacks may indicate a more conducive context to participation. Past research indicating that living in a black neighbourhood may be conducive to the social participation of African Americans (see Bledsoe, Welch, Sigelman, \& Combs, 1995). While we expect that percent black and percent poor will be highly correlated, there will be variation amongst neighbourhoods. For example, there will be relatively middle class neighbourhoods that vary on the percentage of blacks that live in the neighbourhood. We would expect that in these cases, those neighbourhoods with a higher percentage of blacks will have higher participation.

\section{Contributions of study}

This study examines, then, the influence of family resources and connections, the continuity in social connections over the life course and neighbourhoods on social connections. Given the importance of social connections to a number of beneficial outcomes, a better understanding of what influences their development is needed.

\section{Method}

\section{Overall research design}

Using longitudinal data from a cohort of children who started their schooling in an inner city Chicago neighbourhood in 1966, we examine the family and individual characteristics related to social connections as an adult at age 32. We also examine how the neighbourhood where one lives influences social connections. We hypothesize that there is continuity in behaviour over the life course, that early family resources and parental social connections relate to later social connections, and that neighbourhood characteristics are associated with social connections in adulthood.

Longitudinal data can help sort out social selection effects on neighbourhood influences on social connectedness. That is, those who live in poor neighbourhoods may have characteristics that would lead to social isolation as well as to living in a poor neighbourhood (Tienda, 1990), a family background of poverty, frequent mobility, or a history of lack of social attachment to family or school could lead to 
both social isolation and residence in a poor neighbourhood. Controlling on these characteristics, allows us to observe the relationship between social isolation and neighbourhood while taking into account the early family context.

\section{Participants}

The data are from the Woodlawn study, a longitudinal community epidemiological study of a cohort of first graders $(N=1242)$ and their mothers that began in $1966-67$ and followed to age $32(N=952)$. Children (and their families) in the first grade classrooms in the nine public and three parochial schools in Woodlawn were recruited to participate in the study. Thirteen families refused to participate. Ten years after first grade (1976), the mothers and their adolescent children were assessed again. In 1992, the former first graders, age $32-34$, were interviewed as young adults. The study procedures were reviewed by the Bloomberg School of Public Health Institutional Review Board and received their approval. The data from the first two waves have been archived at the Murray Center, Radcliffe Institute for Advanced Studies.

When the study was initiated Woodlawn was one of the poorest of the 76 communities in Chicago with high rates of poverty. According to Census data from Woodlawn and the City of Chicago, $32 \%$ of Woodlawn families with children below the age of 18 were poor compared to $15 \%$ for Chicago. Woodlawn was mostly African American (96\% compared to 33\% for Chicago). It was overcrowded with a population of about 81,000 residents in housing units meant for about 50,000 people. Despite the overall poverty in the neighbourhood, there were areas where middle-class families lived and areas of relatively low unemployment and poverty.

By the time of young adulthood, $84 \%$ of those who were interviewed ( $N=952,48 \%$ male) were living in the Chicago area; only $10 \%$ were still living in the community of Woodlawn. Rates of poverty were high within the population with $39 \%$ living below the poverty threshold. About $80 \%$ had finished high school and $63 \%$ were employed. About $36 \%$ were married and $61 \%$ had children living in their households. However, there was heterogeneity in the population with $10 \%$ having graduated from college.

\section{Attrition}

In any longitudinal study, there is the question of whether those who refuse to continue to participate or who cannot be found are different than other participants who are found and who consent to be interviewed. In the follow-up of the young adults (in 1992 - 1993), we were able to locate $1038(84 \%)$ of the original 1242 who participated as first graders in 1966 - 67. Of these we interviewed 952. Of the remaining 86 located persons, 44 were deceased, 3 were too physically or mentally incapacitated to be interviewed, and 39 refused consent to be interviewed.

We have compared those who were interviewed as young adults to those who were not on earlier ratings of childhood behaviour, social adaptation, and psychological well-being measured during elementary school years and rated by teachers and mothers and on family measures of poverty, family type, mother's education, welfare status, number of residential moves made by the family, and age of mother at birth of her first child as reported by the mothers in first grade. Those whose families had been living below the poverty line in 1966 - 67 were less likely to be interviewed as young adults. Those interviewed as young adults were slightly more likely to have been living with both parents in first grade as compared to those who were not interviewed. None of the other family background measures were related to interview status, and nor were any of the first grade teachers' behaviour ratings or grades. Adolescent drug use did not differentiate those who were re-interviewed from those who were not.

A main source of missing data for the current study comes from the adolescent data. We only interviewed those who lived in Chicago and whose mothers agreed for them to participate. We were able to interview 939 of the mothers $(75 \%)$ and 705 of the adolescents. In comparing those who were assessed in adolescence with those who were not, we found few differences. Missingness during adolescence was not related to gender, mother's education, poverty, welfare, family income, or family type during first grade. Nor was it related to depressive disorder, having an official crime record (overall, or for property, violent, or drug related crime), adult alcohol or drug dependence, or marijuana, cocaine, or heroin use during adulthood. It was related to having a teenage mother - those mothers who started childbearing as a teenager were less likely to give permission for their child to be 
interviewed. Many methodologists have argued that the seriousness of missing data is exaggerated in longitudinal research (Falaris \& Peters, 1998; Fitzgerald, Gottschalk, \& Moffitt, 1998). They suggest that while some of the missing is due to bias (as we show above) that most is due to random factors (as we also demonstrate). Our study has the advantage of being able to compare those who are missing in adolescence not only on the early measures, but also on later measures in adulthood as many were reinterviewed in adulthood.

\section{Measures}

We use five measures of social connectedness in adulthood: political ties, social ties to organizations, church attendance, social supports from family, and social supports from friends and neighbours. Three of these indicate the involvement of the individual with mainstream organizations or activities (political ties, social organizations and church attendance - indicators of "weak ties"). The other two indicate involvement with more immediate friends and family (See Table 1).

Political ties were measured by questions concerning the political behaviour of the young adult. Respondents were asked whether they were registered to vote, ever voted, voted in a recent election, have ever gone to a political meeting, have ever worked in a campaign, ever participated in picketing, sit-ins, and ever signed petitions or written to elected officials $(0=$ no, $1=$ yes). These items represent increasing involvement in the political process. Someone who has voted would also be registered to vote, and someone who has worked in a political campaign would also have been likely to be registered and to have voted. We used Rasch analysis that provides estimates of item difficulty levels along a unidimensional continuum, scaling them against respondent positions on the latent construct being measured (Rasch, 1983). The assessment of "ever signed petitions or written to elected officials" was a departure from the unidimensional measure, so it was omitted from the scale. The 6-item scale of political ties had a moderately high reliability $($ Cronbach's $\cdot=0.76)$. Those who are more involved have a higher score, range -4.11 to 3.75 . This measure is similar to others in the literature used at about the same time as the adult follow-up (e.g. Danigelis, 1982; Jennings \& Markus, 1988).

Social ties to organizations were measured by a series of questions that asked about voluntary community and professional/work organizations that respondents may belong to and whether they participate in the activities of the organization. We focus on those organizations that would be likely to link individuals to others outside their immediate milieu, including (a) professional or labour organizations, (b) civil rights organizations, (c) a national sorority or fraternity, (d) women's rights organizations, or (e) Veteran's groups. The yes responses to belonging and to participating, were summed to make an index of social ties ranging from 0 to 8 . Due to being highly skewed to the right, we combined the higher ratings $(0=$ did not belong or attend) to 4 ( $=$ participated and belonged to more than 4). These measures are similar to those used by others (e.g. Woodward, 1986; Rietschlin, 1998).

Church involvement was measured by asking young adults whether they belonged to church and how often they attended church. The scale ranged from do not belong and never attended church $(=0)$ to belong and attend several times a week $(=4)$. Again, this measure is similar to others' measures of church participation (Ellison \& Sherkat, 1995; Stolzenberg, Blair-Loy, \& Waite, 1995).

Social support is intended to measure the relationships that individuals can draw upon to cope with daily problems (Berkman et al, 2000; Thoits, 1995). Social supports from family and from friends were measured by asking: "To whom you can turn: (a) if you are sick; (b) if you need money; (c) if you have a tough decision to make; (d) if you are sad or blue; and (e) if you have a fight with a friend." Respondents listed those people they could turn to for each of these. Multiple answers were allowed (i.e. someone could answer multiple family members, friends, neighbours). If respondents listed family members (e.g. father, mother, spouse/partner, brother/sister) and other relatives, the yes responses were summed to make a scale of social supports from family and relatives ranging 0 to 25 . Due to highly skewed distribution to the right and wide range of the variable, we used a square root transformation with range of 0 to 5 . If they listed friends or neighbours, the yes responses were summed to make a scale of social supports from friends and neighbours ranging from 0 to 10 . Because these responses were also skewed to the right, we have combined those with more neighbours and friends into fewer categories. The scale ranged from 0 to $5(=5+)$.

Family and individual characteristics in first grade, adolescence, and concurrently in young adulthood were included. Background family variables were mother's education, as reported by the mother at the time of first grade (which was dichotomized as to having finished high school or not) and first grade 
poverty, as indicated by whether the family income was below the federal poverty line reported by the mother. Gender was included. Participants were all African American and of the same age.

Social adaptation in first grade was measured by teacher ratings in first grade on five tasks (i.e. achievement, concentration, social withdrawal [shyness], authority acceptance [aggressiveness], and maturity) the teachers considered important for first graders (see Kellam et al, 1975 for issues of reliability and validity of these ratings). Ratings on social contact (shy behaviour) and authority acceptance (aggressive behaviour) are included here because of their special relevance to the issues of social connectedness. Each first grader was rated on these behaviours on a scale from 0 (neither shy nor aggressive) to 3 (both shy and aggressive). These ratings have been shown in past analyses to relate to adolescent drug use and delinquency and drug use in young adulthood (Ensminger, Juon, \& Fothergill, 2002; Kellam, Ensminger, \& Simon, 1980). Shy behaviour would indicate that the child at the time of first grade was not as involved in social relationships as other children, according to the teacher, and aggressive behaviour indicates that the child related to others in an aggressive or bullying manner, according to the teacher. Adolescent school bonds were assessed by five questions (i.e. how important is doing well in school, how do your teachers think you are doing, how satisfied are you with your teachers' opinion, how far would you like to go in school, and how far do you think you will go in school) about the adolescents' attachments and commitments to school (Cronbach's $\cdot=.68$ ). This measure was trichotomized into low, medium, and high school bonds.

During adolescence, mothers (or mother surrogates) were asked about both their membership and their participation in voluntary associations, and a scale was made that included both the number of associations and their involvement. (This scale is identical to the one described earlier for the young adults). Mothers were also asked about their church membership and frequency of their church attendance (again, similar to the scale described above for the young adults).

The young adult's social class was defined by poverty level and employment. This definition is consistent with those who emphasize attachment to the labour force as an important feature of class position (Wilson, 1987; Tienda \& Stier, 1991; Fernandez \& Harris, 1992). Three groups were defined: (a) the working nonpoor were those with a family income more than $150 \%$ of the official poverty line and who were currently working; (b) the working poor were those with a family income less than $150 \%$ of the official poverty line who were currently working; and (c) the nonworking poor were those with a family income less than $150 \%$ of the poverty line who were not currently working.

Frequent measures of social connections used in the literature (Berkman et al. 2000; House, Landis, \& Umberson, 1988) include marital status and residential mobility. Marital status indicates social connectedness and also facilitates other social involvements. Those who are married have access to the family and friends of their marital partner. Frequent residential mobility can impair the likelihood of the formation or maintenance of friendship and family ties, as well as the participation in community and neighbourhood organizations. The young adults were asked about their current marital status (married vs. not married) and how long they had lived in their current residence.

Neighbourhood characteristics were based on the 1990 census characteristics of the tract where the study participants lived in 1992. The census measures included the proportion of residents who were black, the percent of those who were below the poverty line, and the percent of those with white collar occupations. We chose percent below the poverty line and percent in white collar occupations because of the importance that the social resources in a neighbourhood may have to opportunities to socially participate. We consider the percent in white collar occupations to be an indicator of how middle class the neighbourhood is. The proportion living in poverty was highly correlated with the proportion of blacks in the census tract $(r=.45, p<.001)$ and the proportion in white collar occupations $(r=-.53, p$ $<.001)$. Because of this multicollinearity, we only include the proportion of blacks and the proportion in white collar occupations in our analyses. 
Table 1. Reports of Background, First Grade Adaptation, Mothers' Social Connections, Adolescent Social Connections, Adult Status, and Measures of Social Connections

\begin{tabular}{|c|c|c|c|}
\hline Variables (Time of Measurement in bold) & $\mathrm{M}$ or $\%$ & SD & Range \\
\hline \multicolumn{4}{|l|}{ First Grade $(n=1242)$} \\
\hline \multicolumn{4}{|l|}{ Gender } \\
\hline Male & $47.8 \%$ & & \\
\hline Female & $52.2 \%$ & & \\
\hline \multicolumn{4}{|l|}{ Mother's education } \\
\hline $0-11$ & $58.2 \%$ & & \\
\hline $12+$ & $41.8 \%$ & & \\
\hline \multicolumn{4}{|l|}{ Poverty index } \\
\hline Poor & $51 \%$ & & \\
\hline Not poor & $49 \%$ & & \\
\hline \multicolumn{4}{|l|}{ Shy/Aggressive Behaviour } \\
\hline Neither Shy nor Aggressive & $52.7 \%$ & & \\
\hline Shy Only & $16.1 \%$ & & \\
\hline Aggressive Only & $16.5 \%$ & & \\
\hline Both Shy and Aggressive & $14.7 \%$ & & \\
\hline \multicolumn{4}{|l|}{ Adolescence } \\
\hline School Bonds $(n=705)$ & 1.05 & 0.83 & $0-2$ \\
\hline Mother's church attendance $(n=939)$ & 1.87 & 1.32 & $0-4$ \\
\hline Mother's organizational membership $(n=939)$ & 1.93 & 1.54 & $0-4$ \\
\hline
\end{tabular}

\begin{tabular}{|c|c|c|c|}
\hline Adulthood (n=952) & & & \\
\hline Social class: & & & \\
\hline not poor & $44.3 \%$ & & \\
\hline working poor & $20.1 \%$ & & \\
\hline nonworking poor & $35.6 \%$ & & \\
\hline Marital status & & & \\
\hline Married/living with partner & $27.9 \%$ & & \\
\hline Not married & $72.1 \%$ & & \\
\hline Length of residence & 2.47 & 1.31 & $0-4$ \\
\hline Neighbourhood characteristics (1990 & & & \\
\hline$\%$ below poverty $(0-94)$ & 27.5 & 19.1 & $0-94$ \\
\hline$\%$ black $(0-100)$ & 74.2 & 35.4 & $0-100$ \\
\hline$\%$ white collar job (15-93) & 56.7 & 12.2 & $15-93$ \\
\hline Reports of Social Connections (Outcon & & & \\
\hline Political ties & 0.31 & 1.78 & $-4.11-3.75$ \\
\hline Organization ties & 1.07 & 1.26 & $0-4$ \\
\hline Church attendance & 1.61 & 1.34 & $0-4$ \\
\hline Social support, family & 2.70 & 1.02 & $0-5$ \\
\hline Social support, friends/neighbours & 1.94 & 1.88 & $0-5$ \\
\hline
\end{tabular}




\section{Analytical Approach}

The research questions are focused on the childhood, family, and neighbourhood predictors of five measures of social connections. The data are longitudinal and nested. For the main analysis we relied on regression analysis using General Estimating Equations (GEE) (Zeger, Liang, \& Albert, 1985). We estimate a multivariate model for each of the measures of social connections that includes early family background (poverty, mother's education), childhood behaviours as rated by teachers (shy and aggressive behaviours), adolescent social connectedness (school bonds), mothers' social connections measured during adolescence (church participation and organization involvement), social class in adulthood, marital status, residential stability, and neighbourhood characteristics $(\%$ poor, $\%$ black, and $\%$ in white collar occupations).

The multivariate analyses needs to account for autocorrelation between individual-level and neighbourhood-level measures of poverty. We supplemented our individual-level data with information on the neighbourhood (census tracts) where the adults resided. Clustered data is complicated by the correlation that typically exists among observations within the same cluster. The similarities (i.e. unobserved shared environments) among people from the same neighbourhoods are not fully captured by macro-level covariates in regression models. When autocorrelation is present, the independence assumption of conventional regression techniques is violated (Zeger, Liang, \& Albert, 1988). To account for this potential lack of independence, we used GEE that relax the assumption of the independence of the nested variables (Zeger, Liang, \& Albert, 1988). We were not focused on how much individual level data contributed to the model compared to neighbourhood level data, but rather whether they each contributed to social connections.

We used ordinary least squares regression analysis with our transformed outcome variables (e.g. organization ties, social support from family, social support from friends/neighbours) in order to achieve more normal residuals (Cohen et al, 2003). We tested the assumption of constant variance and found that the data were consistent with this assumption.

A multiple imputation procedure was implemented by using MICE in Stata 10 (StataCorp, 2007). A total of 5 imputed data sets were used in the analysis. Imputation models included all covariates from childhood, adolescence, and young adulthood that were related to the missing mechanism and were associated with social connections. Based on a mixture of dichotomous and ordinal variables, we imputed under an assumption of normality and rounded off the continuous imputes to the nearest categories (Schafer, 1997). We compared the results of the multiple imputation $(n=950)$ with that of listwise deletion $(n=660)$ and found the results were comparable; however, the imputed data had lower standard errors, resulting in larger coefficients and smaller $p$-values.

\section{Results}

Table 2 shows the results of the full multivariate GEE analyses for the five dependent variables. In terms of family background and childhood behaviour measured at the time of first grade, those whose mothers were more educated were more likely to have organizational ties. Those who were shy were less likely to have organization ties than those who were neither shy nor aggressive $(p=.07)$. Those who were aggressive in first grade were less likely to have social supports from family as young adults $(p=.06)$. Those who were rated with the combination of shy and aggressive were less likely to have social supports from either friends or family.

In relation to social connections during the young adults' adolescence, higher school bonds were related to higher church attendance as an adult. The mothers' report of their own church membership was related to adult children's higher likelihood of attending church. Mothers' church participation was inversely related to the adult children's political ties, the only finding that was contrary to intergenerational continuity.

Those who were unemployed and poor had fewer social connections by all measures compared to those who were not poor. The employed poor were less likely to report political ties $(p=.08)$, organizational ties, and social support from family and friends/neighbours compared to those who were not poor.

Neighbourhood context was also found to be associated with adult social connections. Those from neighbourhoods with a higher percentage of blacks were more likely to be politically involved, to attend 
church, and to report social supports from family. Those from neighbourhoods with a higher proportion of residents in white collar occupations were more socially connected on all measures except supports from family.

Individual background variables that served as controls in the analysis were also found to be related to adult social participation. Men were less likely to attend church and to receive social support from friends and neighbours. Those who were married had more organizational ties, higher church participation, and more social support from family. Those with lower residential mobility reported more organizational ties, higher church participation, and more social support from both family and friends.

Table 2. Multivariate Linear Regression Analysis of Social Connections using GEE, b coefficients $(\mathbf{n}=950)$

\begin{tabular}{|c|c|c|c|c|}
\hline $\begin{array}{c}\text { Political } \\
\text { Ties }\end{array}$ & $\begin{array}{c}\text { Organization } \\
\text { Ties }\end{array}$ & $\begin{array}{c}\text { Church } \\
\text { Attendance }\end{array}$ & $\begin{array}{l}\text { Social Support } \\
\text { family }\end{array}$ & $\begin{array}{c}\text { Social Support } \\
\text { friends, } \\
\text { neighbours }\end{array}$ \\
\hline
\end{tabular}

\begin{tabular}{|c|c|c|c|c|c|}
\hline \multicolumn{6}{|c|}{ Individual and Family Background, First Grade } \\
\hline Male & .03 & $-.13+$ & $-.21^{*}$ & -.02 & $-.37^{* *}$ \\
\hline Poverty index $=$ Yes & -.03 & .03 & .12 & -.10 & -.16 \\
\hline Mother's Education $=12$ years + & -.04 & $.17^{*}$ & -.05 & .06 & -.14 \\
\hline \multicolumn{6}{|l|}{ Shy/aggressive behaviour } \\
\hline Shy only & -.14 & $-.19+$ & -.17 & .06 & -.25 \\
\hline Aggressive only & .16 & .08 & -.07 & $-.16+$ & -.08 \\
\hline - Both & .07 & .05 & .14 & $-.22^{*}$ & $-.46^{*}$ \\
\hline \multicolumn{6}{|l|}{ Adolescent social connectedness } \\
\hline School bonds & .15 & .10 & $.18^{* *}$ & .07 & .13 \\
\hline \multicolumn{6}{|c|}{ Mother's social connections at Adolescence } \\
\hline Church membership & $-.11 *$ & .04 & $.12^{* *}$ & -.04 & -.02 \\
\hline Organizational membership & $.08+$ & .03 & .03 & .03 & .01 \\
\hline \multicolumn{6}{|c|}{ Individual and Family Characteristics, Young Adult } \\
\hline Married & .06 & $.45^{* *}$ & $.33^{* *}$ & $.58^{* *}$ & $-.26+$ \\
\hline Length of Residence & $.08+$ & $.08 * *$ & $.08^{*}$ & $.06^{*}$ & $.14^{* *}$ \\
\hline \multicolumn{6}{|l|}{ Poverty and Work, Young Adult } \\
\hline \multicolumn{6}{|l|}{ Social class } \\
\hline Employed poor & $-.31+$ & $-.38^{* *}$ & -.05 & $-.26 * *$ & $-.46^{* *}$ \\
\hline Unemployed poor & $-.81^{* *}$ & $-.59 * *$ & $-.27^{*}$ & $-.28^{* *}$ & $-.43^{* *}$ \\
\hline \multicolumn{6}{|l|}{ Neighbourhood Characteristics } \\
\hline$\%$ Black & $.78^{* *}$ & .26 & $.28^{*}$ & $.23^{*}$ & .27 \\
\hline$\%$ White collar & $1.81^{* *}$ & $.89 *$ & $.82^{*}$ & -.18 & $1.32^{* *}$ \\
\hline
\end{tabular}

Note. $+\mathrm{p}<.10 ;{ }^{*} \mathrm{p}<.05 ;{ }^{*} \mathrm{p}<.01$ 


\section{Discussion}

\section{Continuity across the life course}

The findings indicated a continuity in social connections across the life course. Behaviours related to social relationships that were rated in first grade by teachers were associated to later self reports of organizational participation and social supports from both family and friends. It may be that the behaviours the teachers observed in first grade were relatively stable across the life course, and inhibited supportive interpersonal relationships. It is also plausible that these teacher-rated behaviours set the trajectory for reinforcement of these behaviours developmentally. For example, an aggressive child is difficult for the teacher and for peers so they respond negatively to the child, who in turn responds negatively so that the behaviour becomes exacerbated and reinforced as the child develops. These early behaviours were related to later informal ties with family and friends. Shy children were also less likely to participate in organizations as adults. Our findings support work by Newman and colleagues (1997) and Asendorph, Denissen, and van Aken (2008) that found that childhood temperament was associated with adult interpersonal functioning. Specifically, children who were rated as undercontrolled or inhibited (similar to shy) had lower levels of social support as young adults (Newman et al, 1997) and aggressive children experienced more conflict in their relationships with their mothers and romantic partners (Asendorph, Denissen, \& van Aken, 2008). In addition, social bonds in adolescence related to church participation as an adult, and indicated that early social attachment to school may help prepare young people to participate later in adult organizations.

The intergenerational continuity in social connections was supported by the findings. Both measures of family participation - the mother's church involvement and organizational ties - were related to the adult children's social connections. Given the importance of church participation in the African American community (Ellison \& Sherkat, 1995), having family involvement at an early age clearly fosters more integration to the larger community. Family modeling as well as early familiarity with social participation, may have influence on the social connections that children learn and carry on to adulthood. There also was a negative finding here, in that mothers' involvement in church was negatively related to political participation of their adult children. However, mothers' organizational involvement was related to political participation. It may be that the continuity is specific here so that church involvement relates to later church involvement while organization involvement relates to later secular involvement, i.e. political participation.

In terms of family resources, we had somewhat mixed results. While we did not find childhood family poverty to be related to any of our five outcomes of adult social connections, mother's education was related to greater organizational ties in young adulthood. We did not examine indirect effects in our analyses and it may be that childhood family poverty was indirectly related to later social connections through its relationship with mother's education, adult social class or other variables used in the analyses. Elucidating how these early family resources impact on later life is an important area for further research. We know that mothers in poor households and mothers with lower education are more likely to be depressed (McLloyd, 1990; Ensminger et al, 2003) and are more likely to be the only child-rearing adult in the family (Cancian \& Reed, 2001). Further, those who are poor can only afford to live in poor neighbourhoods where the quality of schooling may be poor and where social control is lacking (Jencks \& Mayer, 1990). This lack of resources may handicap their children in fundamental ways, including their likelihood of participating in both formal and informal relationships.

\section{Adult associations with social connectedness}

One's own resources as an adult greatly influenced social participation. Those who were unemployed but not poor were less likely to report social involvement in all domains except church. Those who were both unemployed and poor were less likely to be socially connected in any domain. One of the underappreciated virtues of economic resources is that they allow participation in civic and voluntary associations and social activities with family and friends that those who are lacking in resources are not as able to easily accomplish. One of the strengths that social capital supposedly brings to children and families is the ability to connect to those who provide opportunities and social resources (Astone et al, 1999). The findings here suggest that, to the extent that social capital is indicated in our measures of social connectedness, social capital is not equally distributed; those who have fewer economic resources are also likely to have less social capital. 
Two of the most commonly found predictors of social integration were also evident in these findings length of residence and marital status. Those who had lived in their current residence for a longer time were more likely to report being socially connected across all five measures of participation. Marriage related to higher organizational and church involvement and more social supports from family, but less social supports from friends and neighbours. Given that current social class and past behaviours were included in these analyses, the results indicate the sturdiness of the marriage and residential stability impact on social connections.

\section{Neighbourhood influences on social participation}

The results are also consistent with the importance of neighbourhood context on social connections, even with individual social class included in the analyses. Living in a middle class neighbourhood and living in a neighbourhood that had a higher proportion of African Americans, increased the likelihood of political participation, church attendance and social supports. These may seem to be contradictory results since neighbourhoods with a higher percentage of blacks are less likely to be middle class. However, in this population of all black respondents, there is not a one-to-one correlation between these neighbourhood variables, and middle class neighbourhoods did vary on the percentage of blacks who lived in the neighbourhood. Those who lived in neighbourhoods with a higher proportion of blacks were more likely to report higher social supports from family, while those living in middle class neighbourhoods reported higher involvement with friends and neighbours. (Since these findings are from multivariate analyses, the significant findings control on the other variables in the analyses). The findings are consistent with the social density hypothesis which predicts stronger racial solidarity among blacks who live in predominantly black neighbourhoods (Bledsoe, Welch, Sigelman \& Combs, 1995). Blacks with a greater sense of solidarity are more likely to engage in a greater variety of political activities (Gurin, Miller, \& Gurin 1980).

\section{Influences on adult family support}

Findings from the study indicate the myriad influences on the reports of family support from young adults. First grade aggressive and shy behaviour, being unmarried, being poor and unemployed as an adult, and living in a neighbourhood with fewer African Americans were all related to having less support from family members as an adult. These findings reflect the complexity that is involved in the formation of social bonds to one's family. These findings emphasize that resources not only matter for material goods but also for primary social relationships.

\section{Strengths and Limitations}

One of the strengths of the study is the number of sources of information and the prospectively collected data. Teachers reported on the child's behaviour in first grade; mothers reported on the family background in first grade and on their own social connections during their child's adolescence; the cohort members reported on their social connections in adolescence, on their residential and marital status in adulthood and on their social connections in adulthood. Finally, census information was used to characterize the neighbourhoods where the adults lived. The conclusion that there are multiple sources of social connections is strengthened by the findings that reports from all these sources were related to the social connections evident in adulthood.

The design of this study has some limitations in examining the origins of social connections. In terms of our neighbourhood findings, our results may be somewhat affected by social selection issues, that is, more socially isolated individuals may be more constrained or may choose to live in neighbourhoods that do not enhance social participation. Social selection hampers many studies of neighbourhood effects as it is very rare to be able to assign people to neighbourhoods. Since this study is a longitudinal study we are able to control on many of the background characteristics that are thought to affect neighbourhood residence such as a family background of poverty, a history of residential mobility, and current economic resources, but we may not have included all the potentially relevant variables.

The results come from one cohort of children from a disadvantaged neighbourhood followed longitudinally to adulthood. Clearly, there are questions of generalizability. However, the population is an important one in terms of formulations about the social isolation of those who live in poor and segregated neighbourhoods. 
Further, there was moderate attrition, especially during the adolescent period. Some of the factors relating to attrition may affect the findings. Those children born to teen mothers were less likely to be assessed during adolescence. There were some indications that teen mothers were more socially isolated - they moved more often, they were less likely to give permission for their children to participate in the study, and their family connections were less stable. These children may have grown to be more isolated as adults and may have been less likely to be interviewed as an adult. However, few other differences were found between those who participated and those who did not.

\section{Implications}

Formal participation and informal participation have often been distinguished in the literature. "Weak" ties are supposedly enhanced by formal participation. In our findings, with the exception of the influence of mothers' social connectedness (which only related to weak ties) there did not seem to be distinct predictors of the two. Otherwise, political, organizational, and church participation were often predicted by the same antecedents as were family and friend supports. There may be more continuity in participation across these domains than has been suggested.

Despite the limitations of the study, this work provides evidence of the complex and multifaceted nature of the origins of social connections. Adult social involvement has many influences over the life course including family resources and family social involvement, past behaviours, current resources, as well as the neighbourhood where one lives. Durkheim's (1951) classic study of suicide pointed us to the social origins of social integration. These social origins are clear in the current work. However, other influences on social connections are also evident. One's family history and earlier experiences of social connectedness also enhance social connections in adulthood.

There are several implications for this work. First, the study of social connections across the life course has received little study. Given the importance of social connections both for the individual and for society, a better understanding of how social connections develop and are sustained should be a priority for longitudinal researchers.

We are cautious about making policy implications. We are well aware that even though this is a longitudinal study with all of its advantages, it is an observational study and the findings need to be replicated in other studies with other populations. However, if the findings do replicate, experimental studies might be designed that would investigate the possibilities of creating social conditions that would enhance the formation of social connections. Neighbourhood opportunities might be enhanced, particularly in disadvantaged neighbourhoods. Elementary and upper level schools might create more choices for children and adolescents to participate in activities. Early prevention programmes that have targeted aggressive behaviour in young children (Bierman et al, 2004; Kellam et al, 2008) may examine the outcomes of social connections as well as the outcomes of drug use, violence, and other negative outcomes.

\section{References}

Asendorph J. B., Denissen J. J. A., \& van Aken, M. A. G. (2008) Inhibited and aggressive preschool children at 23 years of age: personality and social transitions into adulthood. Developmental Psychology, 44, 997 - 1011.

Astone, N. M., Nathanson, C. A., Schoen, R., \& Kim, Y. J. (1999) Family demography, social theory, and investment in social capital. Population and Development Review, 25, 1 - 31.

Berkman, L. F., Glass, T., Brissette, I., \& Seeman, T. E. (2000) From social integration to health: Durkheim in the new millennium. Social Science \& Medicine, 51, $843-857$.

Bierman, K. L., Coie, J. D., Dodge, K. A., Foster, E. M., Greenberg, M. T., Lochman, J. E., McMahon, R. J., \& Pinderhughes, E. E. (2004). The effects of the Fast Track program on serious problem outcomes at the end of elementary school. Journal of Clinical Child and Adolescent Psychology, 33, 650 - 661.

Blau, P. \& Duncan, O. D. (1967) The American occupational structure. The Free Press, New York. 
Bledsoe, T., Welch, S., Sigelman, L., \& Combs, M. (1995) Residential context and racial solidarity among African Americans. American Journal of Political Science, 39, 434 - 458.

Burton, R. P. D. (1998) A global integrative meaning as a mediating factor in the relationship between social roles and psychological distress. Journal of Health and Social Behavior, 30, 201 - 215.

Cancian, M., \& Reed, D. (2001) Changes in family structure: implications for poverty and related policy. In Danziger, S. H., \& Haveman, R. H. eds. Understanding poverty. Pp. 69 - 96. Harvard University Press, Cambridge, MA.

Cohen, J., Cohen, P., West, S. G., \& Aiken, L. S. (2003) Applied multiple regression/correlation analysis for the behavioral sciences, third edition. Lawrence Erlbaum Associates, Mahwah, New Jersey.

Coleman, J. S. (1988) Social capital in the creation of human capital. American Journal of Sociology, 94, S95- 121.

Danigelis, N. L. (1982) Race, class, and political involvement in the U. S. Social Forces, 61, $532-550$.

Durkheim, E. (1951) Suicide: a study in sociology. Translated by Spaulding, J. A., \& Simpson, G. The Free Press, New York.

Elder Jr., G. H. (1998) The life course as developmental theory. Child Development, 69, 1 - 12.

Ellaway, A., \& Macintyre, S. (2007) Is social participation associated with cardiovascular disease risk factors? Social Science \& Medicine, 64, 1384 - 1391.

Ellison, C. G., \& Sherkat, D. E. (1995) The "semi-involuntary institution" revisited: regional variations in church participation among Black Americans. Social Forces, 73, 1415 - 1437.

Ensminger, M. E., Juon, H. S., \& Fothergill, K. E. (2002) Childhood and adolescent antecedents of substance use in early adulthood. Addiction, 97, $833-844$.

Ensminger, M. E., Hanson, S. G., Riley, A. W., \& Juon, H. S. (2003) Maternal psychological distress: adult sons' and daughters' mental health and educational attainment. Journal of the American Academy of Child and Adolescent Psychiatry, 42, $1108-1115$.

Falaris, E. M., \& Peters, H. E. (1998) Survey attrition and school choices. Journal of Human Resources, $33,531-554$.

Fernandez, R. M., \& Harris, D. (1992) Social isolation and the underclass. In Harrell, A.V., \& Peterson, G. E. eds. Drugs, crime, and social isolation. Pp. 257 - 295. The Urban Institute Press, Washington, DC.

Fitzgerald, J., Gottschalk, P., \& Moffitt, R. (1998) An analysis of sample attrition in panel data:

The Michigan panel study of income dynamics. Journal of Human Resources, 33, 251 - 259.

Furstenberg, F. F., \& Hughes, M. E. (1995) Social capital and successful development among at-risk youth. Journal of Marriage and the Family, 57, 580 - 592.

Granovetter, M. (1973) The strength of weak ties. American Journal of Sociology, 78, 1360 - 1389.

Graves, P. L., Wang, N., Mead, L. A., Johnson, J. V., \& Klag, M. J. (1998) Youthful precursors of midlife social support. Journal of Personality and Social Psychology, 74, 1329 - 1336.

Gurin, P., Miller, A. H., \& Gurin, G. (1980) Stratum identification and consciousness. Social Psychology Quarterly, 43, 30 - 47.

Harding, D. J., Jencks, C., Lopoo, L. M., \& Mayer, S. E. (2005) The changing effect of family background on the incomes of American adults. In Bowles, S., Gintis, H., \& Osborne, M. eds. Unequal chances, family background and economic success. Pp. 100 - 144. Russell Sage Foundation, New York. 
Hirschi, T. (1969) Causes of delinquency. University of California Press, Berkeley, CA.

House, J. S., Landis, K. R., \& Umberson, D. (1988) Social relationships and health. Science, 4865, 540 545.

Institute of Medicine. (2003) The future of the public's health in the 21st century. The National Academies Press, Washington, DC.

Jencks, C., \& Mayer, S. (1990) The social consequences of growing up in a poor neighborhood. In Lynn, L., \& McGreary, M. eds. Inner city poverty in the United States. Pp.111 - 186. National Academy Press, Washington, DC.

Jennings, M. K., \& Markus, G. B. (1988) Political involvement in the later years: A longitudinal survey. American Journal of Political Science, 32, 302 - 316.

Kasinitz, P., \& Rosenberg, J. (1996) Missing the connection: Social isolation and employment on the Brooklyn waterfront. Social Problems, 43, 180 - 196.

Kellam, S. G., Branch, J. D., Agrawal, K. C., \& Ensminger, M. E. (1975) Mental health and going to school: the Woodlawn program of assessment, early intervention, and evaluation. The University of Chicago Press, Chicago.

Kellam, S. G., Ensminger, M. E., \& Simon, M. B. (1980) Mental health in first grade and teenage drug, alcohol and cigarette use. Drug and Alcohol Dependence, 5, 273 - 304.

Kellam, S. G., \& Rebok, G. W. (1992) Building developmental and etiological theory through epidemiologically based preventive intervention trials. In McCord, J., \& Tremblay, R. E. eds. Preventing antisocial behavior: interventions from birth through adolescence. Pp. 162 - 195. Guilford, New York.

Kellam, S. G., Brown, C. H., Poduska, J. M., lalongo, N. S., Wang, W., Toyinbo, P., Petras, H., Ford, C., Windham, A., \& Wilcox, H. C. (2008) Effects of a universal classroom behavior management program in first and second grades on young adult behavioral, psychiatric, and social outcomes. Drug and Alcohol Dependence, 95S, S5 - S28.

Kinder, D. R. (2006) Politics and the life cycle. Science, 312, 1905 - 1908.

Lindstrom, M., Moghaddassi, M., Bolin, K., Lindgren, B., \& Merlo, J. (2003) Social participation, social capital and daily tobacco smoking: a population-based multilevel analysis in Malmo, Sweden. Scandinavian Journal of Public Health, 31, $444-450$.

McLloyd, V. C. (1990) Minority children: introduction to the special issue. Child Development, 61, $263-$ 266.

Myers, S. M. (1999) Childhood migration and social integration in adulthood. Journal of Marriage and the Family, 61, $774-789$.

Newman, D. L., Caspi, A., Moffitt, T. E. \& Silva, P. A. (1997) Antecedents of adult interpersonal functioning: effects of individual differences in age 3 temperament. Developmental Psychology, 33, 206 $-217$.

Oliver, M. L. (1988) The urban black community as network: toward a social network perspective. Sociological Quarterly, 29, $623-645$.

Portes, A. (1998) Social capital: its origins and applications in modern sociology. Annual Review of Sociology, 24, $1-24$.

Rasch, G. (1980) Probabilistic models for some intelligence and achievement test. Danish Institute for Educational Research, Copenhagen. 
Rankin, B. H., \& Quane, J. M. (2000) Neighborhood poverty and the social isolation of inner-city African American families. Social Forces, 79, $139-164$.

Runyan, D. K., Hunter, W. M., Socolar, R. R., Amaya-Jackson, L., English, D., Landsverk, J., Dubowitz, H., Browne, D. H., Bangdiwala, S. I., \& Matthew, R. M. (1998) Children who prosper in unfavorable environments: the relationship to social capital. Pediatrics, 101, $12-18$.

Rietschlin, J. (1998) Voluntary association membership and psychological distress. Journal of Health and Social Behavior, 39, 348 - 355.

Rosenstone, S. J., \& Hansen, J. M. (1993) Mobilization, participation and democracy in America. Macmillan, New York.

Sampson, R. J., \& Laub, J. H. (1993) Crime in the making: pathways and turning points through life. Harvard University Press, Cambridge, MA.

Seeman, T. E. (1996) Social ties and health: the benefit of social integration. Annals of Epidemiology, 6, $442-451$.

StataCorp. (2007) Stata statistical software: release 10. StataCorp LP, College Station, TX.

Stolzenberg, R. M., Blair-Loy, M., \& Waite, L. J. (1995) Religious participation in early adulthood: Age and family life cycle effects on church membership. American Sociological Review, 60, 84 - 103.

Thoits, P. (1995) Stress, coping, and social support processes: where are we? What next? Journal of Health and Social Behavior, Special Issue, $53-79$.

Tienda, M. (1990) Poor people and poor places: deciphering neighborhood effects on poverty outcomes. In Huber, J. ed. Macro-micro linkages in sociology. Pp.244 - 262. Sage, Newbury Park, CA.

Tienda, M. \& Stier, H. (1991) Joblessness and shiftlessness: labor force activity in Chicago's ghetto poverty neighborhoods. In Jencks, C., \& Peterson, P.E. eds. The urban underclass. Pp. 135 - 154. Brookings Institution, Washington, DC.

Umberson, D. (1987) Family status and health behaviors: social control as a dimension of social integration. Journal of Health and Social Behavior, 28, 306 - 319.

Wilson, W. J. (1987) The truly disadvantaged: the inner city, the underclass, and public policy. University of Chicago Press, Chicago.

Woodward, M. D. (1986) Voluntary association membership among Black Americans: the post-civil rights era. The Sociological Quarterly, 28, 285 - 301.

Zeger, S. L., Liang, K., \& Albert, P. S. (1988) Models for longitudinal data: a generalized estimating equation approach. Biometrics, 44, $1049-1060$. 